\title{
Peripheral neuropathy in HIV patients in sub-Saharan Africa failing first-line therapy and the response to second line ART in the EARNEST trial
}

\author{
Alejandro Arenas-Pinto ${ }^{1}$ \\ Jennifer Thompson ${ }^{1}$ \\ Godfrey Musoro ${ }^{2}$ \\ Hellen Musana ${ }^{3}$ \\ Abbas Lugemwa ${ }^{4}$ \\ Andrew Kambugu ${ }^{5}$ \\ Aggrey Mweemba ${ }^{6}$ \\ Dickens Atwongyeire ${ }^{7}$ \\ Margaret J. Thomason ${ }^{1}$ \\ A. Sarah Walker ${ }^{1}$ \\ Nicholas I. Paton ${ }^{8,1}$ \\ For the EARNEST Trial Team 9
}

${ }^{1}$ MRC Clinical Trials Unit at UCL, London, United Kingdom; ${ }^{2}$ University of Zimbabwe Clinical Research Centre, Harare, Zimbabwe; ${ }^{3}$ Joint Clinical Research Centre (JCRC), Kampala, Uganda; ${ }^{4} J o i n t$ Clinical Research Centre (JCRC), Mbarara, Uganda; ${ }^{5}$ Infectious Diseases Institute, Makerere University, Kampala, Uganda; ${ }^{6}$ University Teaching Hospital, Lusaka, Zambia; ${ }^{7} J o i n t$ Clinical Research Centre (JCRC), Kakira, Uganda; ${ }^{8}$ National University of Singapore, Singapore, Singapore

१Members of the Europe Africa Research Network for Evaluation of Second-line Therapy (EARNEST) Trial Team are listed in the Appendix

\section{Word count: 2,993 (Tables 3, Figures 2)}

Abstract: 250

References: 34

Correspondence to: Alejandro Arenas-Pinto, MRC Clinical Trials Unit at UCL, Institute of Clinical Trials \& Methodology, Aviation House, 125 Kingsway, London WC2B 6NH, U.K.

E-mail: A.Arenas-Pinto@ucl.ac.uk 


\section{ABSTRACT}

Sensory peripheral neuropathy (PN) remains a common complication in HIV-positive patients despite effective combination anti-retroviral therapy (ART). Data on PN on second-line ART is scarce. We assessed PN using a standard tool in patients failing first-line ART and for 96 weeks following a switch to PI-based second-line ART in a large Randomised Clinical Trial in Sub-Saharan Africa. Factors associated with PN were investigated using logistic regression. Symptomatic PN (SPN) prevalence was $22 \%$ at entry $(N=1251)$ and was associated $(p<0.05)$ with older age $(O R=1.04$ per year), female gender ( $O R=1.64)$, Tuberculosis ( $T B)(O R=1.86)$, smoking $(O R=1.60)$, higher plasma creatinine ( $O R=1.09$ per $0.1 \mathrm{mg} / \mathrm{dl}$ increase), $\mathrm{CD} 4$ count (OR=0.83 per doubling) and not consuming alcohol $(O R=0.55)$. SPN prevalence decreased to $17 \%$ by week $96(p=0.0002)$ following similar trends in all study groups $(p=0.30)$. Asymptomatic PN (APN) increased over the same period from $21 \%$ to $29 \%$ $(p=0.0002)$. Signs suggestive of PN (regardless of symptoms) returned to baseline levels by week 96 . At weeks 48 and 96, after adjusting for time-updated associations above and baseline CD4 count and viral load, SPN was strongly associated with TB $(\mathrm{p}<0.0001)$. In summary, SPN prevalence was significantly reduced with PI-based second-line therapy across all treatment groups, but we did not find any advantage to the NRTI-free regimens. The increase of APN and stability of PN-signs regardless of symptoms suggest an underlying trend of neuropathy progression that may be masked by reduction of symptoms accompanying general health improvement induced by second-line ART. SPN was strongly associated with isoniazid given for TB treatment. 


\section{INTRODUCTION}

Sensory peripheral neuropathy (PN) remains one of the most common complications in HIV-positive patients despite the use of effective combination anti-retroviral therapy (CART)(Ellis et al., 2010; Kamerman, Wadley, \& Cherry, 2012). Prevalence of symptomatic PN in HIV-positive individuals has been reported to range between $20-60 \%$ in cross-sectional studies and has been associated with several factors. PN is a complication of HIV disease progression in ART-naïve patients but can also be aggravated by ART-induced immune restoration, where greater CD4 cell count recovery has been associated with an increased risk of developing PN(Childs et al., 1999; Ellis et al., 2010; Maritz et al., 2010). However, more often it has been reported as adverse reaction to dideoxynucleosides or "ddrugs", particularly stavudine (d4T) and didanosine (ddl)(van Oosterhout et al., 2012; Wadley, Cherry, Price, \& Kamerman, 2011; Wright et al., 2008) which until relatively recently were frequently used in Sub-Saharan African countries. Other drugs frequently used in HIV-positive individuals such as isoniazid can also cause similar neuropathic symptoms(van der Watt, Harrison, Benatar, \& Heckmann, 2011). Clinical presentation of HIV-induced and toxicity-associated PN are often indistinguishable and regardless of its cause PN has a significant negative impact on the quality of life of HIV-positive adults(Biraguma \& Rhoda, 2012; Ellis et al., 2010).

In ART-naïve patients, signs of PN appear to persist after initiation of effective cART and increase over-time(D. Evans, Takuva, Rassool, Firnhaber, \& Maskew, 2012; S. R. Evans et al., 2011). Incidence of new PN while on first-line CART has been estimated to range between 12 to 21 cases per 100 person-years but association between "d-drug" exposure and persistent or incident PN during firstline therapy has been inconsistently reported(S. R. Evans et al., 2011; Mehta et al., 2011; Nakamoto et al., 2010). In ART-experienced patients PN appears to remain a major problem despite effective virological control(Chen et al., 2013b). Little is known about prevalence of and risk factors for PN in ART-experienced patients failing first-line ART or how PN changes on protease inhibitor (PI)-based second-line ART in resource-limited settings. We therefore conducted an analysis to investigate this in a large clinical trial in sub-Saharan Africa.

\section{METHODS}

\section{Participants and setting}

The EARNEST trial was a large, open-label, randomised clinical trial (ISRCTN-37737787), performed in 14 centres in sub-Saharan Africa where HIV-positive adult and adolescent patients with virological, immunological or clinical first-line CART failure were randomised to lopinavir/ritonavir $400 \mathrm{mg} / 100 \mathrm{mg}$ twice daily with either (i) 2-3 new or recycled NRTIs chosen by the treating physician ("PI/NRTI"); (ii) raltegravir 400mg twice daily ("PI/RAL"); or (iii) raltegravir induction for the first 12 weeks only ("PImono"). The main analysis of the trial has been reported elsewhere(Paton et al., 2014). In summary, the $\mathrm{PI} / \mathrm{NRTI}$ arm and PI/RAL arm were indistinguishable on the primary composite endpoint (clinical, immunological and virological components) and produced identical rates of VL suppression at 96 weeks ( $86 \%<400$ copies $/ \mathrm{ml}$ ). The PI-mono arm was similar to PI/NRTI on clinical and CD4 components of the composite endpoint, but VL suppression was substantially worse $(61 \%<400$ copies at 96 weeks). The study (which included neuropathy assessments as part of the main protocol in all patients) was approved by all relevant ethics committees and regulatory 
agencies in participating countries and in the UK. All participants or caregivers provided written informed consent.

Participants were assessed for PN using the AIDS Clinical Trials Group (ACTG) Brief Peripheral Neuropathy Screen tool (BPNS)(Cettomai et al., 2010; Marra, Boutin, \& Collier, 1998) at baseline, week 48 and week 96. Symptomatic PN (SPN) was defined as presence of bilateral neuropathic symptoms (at least one of pain, aching or burning, pins and needles, or numbness) and abnormal signs (either reduced or absent ankle reflex or reduced vibration sense at the great toe (vibration of a 128- $\mathrm{Hz}$ tuning fork felt for 10 seconds or less))(Ellis et al., 2005; S. R. Evans et al., 2011). Asymptomatic PN (APN) was defined as reduced or absent ankle reflex or reduced vibration sense at the great toe without symptoms. Site investigators were trained on the BPNS tool at site initiation visits.

In addition, medical assessment at these study visits included symptom review, physical examination, full blood count, serum creatinine levels and CD4 counts. HIV-RNA was measured centrally (Joint Clinical Research Centre, Kampala, Uganda) on stored plasma samples.

\section{Statistical analysis}

All statistical tests presented are two-sided. All analyses were carried out in Stata version 13.1. Association between $\mathrm{PN}$ and patient characteristics at switch to second-line, including demographics, study site, anthropometric measures, CD4 cell count, HIV-RNA level, WHO HIV disease stage, ART exposure, co-morbidities (such as TB, diabetes mellitus, and cardiovascular disease(CVD)), concomitant medication in the last 10 weeks, alcohol consumption, smoking status, and socio-economic variables including household income and employment status were modelled using complete case univariable logistic regression with fractional polynomials to allow for nonlinear relationships between continuous factors and PN. Years on first-line ART and creatinine were censored at approximate $99^{\text {th }}$ percentiles to reduce the impact of outliers. Centre effects were estimated pooling sites with similar overall prevalence (Table 1) to prevent perfect prediction in low prevalence sites. Primary analyses excluded 19 participants from the smallest centre that reported very high and potentially implausible rates of PN on symptom report (12/19 63\%) and abnormal signs (17/17 with completed PN signs, 100\%).

Factors associated with $\mathrm{PN}$ status univariably with $\mathrm{P}<0.2$ were included in a multivariable logistic regression. Backward selection (exit criteria $\mathrm{P}>0.1$ ) was used to select independent risk factors using fractional polynomials to allow for non-linear relationships (Stata mfpmi command). Multiple imputation using chained estimating equations (Stata ice command) was used to impute a small amount of missing data in risk factors and components of PN (if at least one component was complete)(van Buuren, Boshuizen, \& Knook, 1999).

Sensitivity analyses were performed (i) on complete cases, (ii) using multiple imputation including the site excluded from the primary analysis, and (iii) abnormal signs (regardless of the presence of symptoms) (iv) symptoms (regardless of the presence of abnormal signs), and (v) bilateral symptoms plus either reduced vibration sense or absent ankle reflex. A repeated measures model (generalized estimating equations, independent correlation structure, binomial distribution) looked at the effect of time updated factors selected in the baseline model as well as baseline CD4 and viral load on PN at weeks 48 and 96 in complete cases. 
Prevalence of SPN, APN, abnormal signs (regardless of the presence of symptoms), and symptoms (regardless of the presence of abnormal signs) were calculated at baseline, week 48 and 96 by study treatment arm in those with complete PN assessment and was compared between the arms at each time point using risk differences and chi squared tests. Generalised estimating equations (independent correlation structure, binomial distribution) were used to test for a difference between the arms across all time points.

\section{RESULTS}

Of the 1277 patients randomised in the EARNEST trial, 19 were from the excluded site, 1 had completely absent baseline PN assessment, and 1 was an amputee so could not be assessed leaving 1256 (98\%) eligible patients. 1251 had a complete PN assessment at baseline. Of these, 726 (58\%) were female and the median age at switch to second-line was 37 years (inter-quartile range (IQR) 31-44). At second-line switch, patients had been on first-line CART for a median of 4 years (IQR 2.85.4); most had been exposed to zidovudine (AZT) (68\%) or d4T (60\%) during first-line, with fewer already exposed to tenofovir disoproxil fumarate (TDF) (14\%). At switch, median CD4 count was 71 cell/mm $3 \mathrm{~mm}^{3}$ (IQR 30-147), median plasma HIV viral load (VL) was 67500 copies/ml (IQR 22818-193000) and $80 \%$ of participants with medical history available had been reported to have at least one WHO stage $3 / 4$ condition (Table 1). In EARNEST 420 participants were randomised to PI/NRTI (TDF in 79\%, abacavir (ABC) in 16\%, ddl in 13\%, d4T in <1\%, lamivudine/emtricitabine (3TC/FTC) in 87\%), 422 to $\mathrm{PI} / \mathrm{RAL}$ and $409 \mathrm{PImono}$ second-line ART.

\section{PN at first-line failure:}

At switch, 279 of the 1251 (22\%) patients with a complete PN assessment met the study definition for SPN and the prevalence of APN was similar at $21 \%$. Overall $44 \%$ of patients had abnormal signs at examination. SPN prevalence differed significantly between study sites ranging from 0 to $44 \%$ $(\mathrm{P}<0.0001)$. However, prevalence of SPN in the three Kampala sites was remarkably similar $(25-28 \%)$ whereas the other six Ugandan sites, located elsewhere in the country, showed also similar but much lower prevalence (0-9\%).

The characteristics of the patients at first line failure and the univariable associations with SPN are shown in Table 1. In the multivariable model, independent associations were found with age, female gender, history of TB, and higher levels of plasma creatinine. The odds of having PN at first line failure were lower with higher CD4 counts and alcohol consumption, whereas smokers were more likely to have SPN at entry (Table 2$)$. Weak evidence $(0.05<p<0.1)$ of associations with increasing risk of SPN were found with viral load, increasing glucose, family history of CVD, TDF or nevirapine (NVP) during first-line, and employment status.

An exploratory analysis considered additional impact on SPN of exposure to d4T and time on d4T. After adjusting for the factors above, $\mathrm{d} 4 \mathrm{~T}$ at any time on first-line (ignoring duration) was not independently associated with SPN $(\mathrm{p}=0.44)$, however adjusting for duration of exposure suggested SPN risk was higher in those with a short exposure, with the risk decreasing with increasing time on 
d4T ( $p=0.007)$ (supplementary material table 3 ). When isoniazid use in the last 10 weeks was included in the model as well as TB these were not independently associated with SPN, and TB was the better predictor of SPN. When substituting TB with isoniazid, the effect of isoniazid was comparable to TB (supplementary material table 4).

Sensitivity analyses that included complete cases, the excluded site, bilateral symptoms and reduced vibration sense or absent ankle reflex, and presence of symptoms gave results similar to those above. There was no evidence of an association between abnormal signs (regardless of symptoms) and sex, TDF exposure, or alcohol. Effects were attenuated compared to the SPN model for VL, CD4, NVP exposure, smoking, family history of CVD, and glucose. The effect of age, TB, creatinine, and employment status remained unchanged and additional associations were identified with $\mathrm{d} 4 \mathrm{~T}$ $(\mathrm{OR}=1.44 ; 95 \% \mathrm{Cl}$ 1.02-2.05; $\mathrm{p}=0.04)$, and height (OR=1.03; 95\% Cl 1.01-1.05; $\mathrm{p}=0.001$ ). (supplementary material table 5 ).

\section{PN on second-line therapy:}

Overall, 135 out of 1176 (11\%) patients assessed at week 48 had SPN ( $P<0.0001$ vs baseline) whereas the prevalence at week 96 was $17 \%(P<0.0001$ vs week 48, $p=0.0002$ vs baseline) (Figure $1(a))$. In contrast, the prevalence of APN showed a steady increase over time $(21 \%, 24 \%$ and $29 \%$ at weeks 0 , 48, 96 respectively; trend $p=0.0002$ ) (figure $1 b$ ). Abnormal signs suggestive of $P N$ had a smaller decline in prevalence at week 48 than SPN (44\%, 36\% at weeks 0, 48 respectively) but returned to baseline levels by week 96 (46\%) (Figure 1c).

As expected, the prevalence of SPN was similar between study groups at entry $(23 \%, 23 \%$ and $22 \%$ in $\mathrm{PI} / \mathrm{NRTI}, \mathrm{PI} / \mathrm{RAL}$ and PImono respectively). There was no difference in SPN prevalence between randomisation arms at week 96 (global $p=0.11$ ) (Table 3). Overall, there was no evidence for differences between study group in the trends over time of any PN outcome measure ( $p>0.1$, Figure 1). At week 48 and 96 there was no effect of baseline or current VL, current CD4, smoking, alcohol consumption, or creatinine. The effect of family history of CVD, glucose at failure, sex, NVP and TDF exposure was attenuated, and baseline CD4, age, TB and job status remained unchanged (Supplementary Table 10). Similarly to baseline, isoniazid and TB were not independently associated with PN and isoniazid remained strongly associated with SPN $(p<0.0001)$ after adjusting for the factors above.

Considering the 1132 participants with PN status assessed at all time-points, the rate of incident SPN was $4 \%$ (38/882 patients with no SPN at baseline) by week 48 and $9 \%$ (75/844 patients without SPN at week 48) by week 96 (Figure 2). Resolution of SPN was observed in 64\% (159/250) of patients with SPN at baseline by week 48 and 31\% (28/91) of patients with persistent SPN at week 48 by week 96. Overall, 58\% (145/250) of the participants with SPN at first line failure had SPN resolution at week 96. Isoniazid-based TB treatment was prescribed during study period to $18 \%$ of patients who developed incident SPN, but only to $6 \%$ of those patients who never developed SPN $(P<0.001)$. However, we found no evidence of pyridoxine reducing the chance of developing SPN since 7/18 (39\%) of those given pyridoxine and 13/48 (27\%) not given it developed SPN ( $p=0.35)$. 


\section{DISCUSSION}

In this large, well-characterised cohort of patients taking part in a randomised controlled trial on PIbased second-line ART that were systematically assessed using a well-validated and objective tool, we observed a prevalence of SPN of $22 \%$ at second-line switch, similar to levels reported in ARTexperienced patients in Sub-Saharan Africa (21\%)(Luma et al., 2012; van Oosterhout et al., 2012) but lower than the prevalence reported at virological failure in the ALLRT study in the USA (33.7\%)(Chen et al., 2013b). ALLRT study participants were assessed using the same tool but were slightly older and had been exposed to ART for longer than those recruited in EARNEST (median (IQR) age at entry 43 (37-48) and 37 (31-44) years and median (IQR) exposure to ART prior entry $6.0(3.0,9.3)$ and 4.0 (2.8-5.4)years respectively) which at least partially explains the differences in SPN prevalence given the consistent associations between these factors and increased risk of SPN(Cherry et al., 2009; Ellis et al., 2010; S. R. Evans et al., 2011).

We found low CD4 count, but not HIV-VL associated with SPN suggesting that immuno-suppression or the incident opportunistic conditions associated with it, and the drugs required for the treatment of these conditions is a key predictor(Ellis et al., 2010; Luma et al., 2012). In particular, we found that history of TB was independently associated with SPN at the time of first-line failure probably reflecting associations between SPN and exposure to anti-TB treatment (Luma et al., 2012; Maritz et al., 2010; van der Watt et al., 2011). Neuropathy is a well-known adverse effect attributable to isoniazid, although rare when used as preventive therapy(Grant et al., 2010). Pyridoxine coadministration effectively reduces the risk of developing isoniazid -induced PN but it is inconsistently prescribed as part of TB treatment in Sub-Saharan Africa (Grant et al., 2010; van der Watt et al., 2011). In EARNEST, only $26 \%$ of patients were prescribed pyridoxine when treated for incident TB. The risk of developing drug-induced $\mathrm{PN}$ is independently and significantly higher in patients simultaneously exposed to isoniazid and d-drugs(Breen et al., 2006; Dean et al., 2002), but appears to peak after the first few months of exposure to these antiretrovirals, and decline thereafter(Arenas-Pinto, Bhaskaran, Dunn, \& Weller, 2008; Dean et al., 2002; Westreich et al., 2009). In our study, adding d4T and duration of exposure to d4T to our final multivariable model similarly found that the risk of presenting SPN decreased with duration of exposure to d4T in first-line, possibly due to only those not affected by SPN remaining on this NRTI for long periods of time (i.e. channelling bias) or due to special susceptibility, probably genetically mediated, to toxic effects induced by d-drugs(Arenas-Pinto et al., 2008; Kampira, Kumwenda, van Oosterhout, \& Dandara, 2013).

Our data do not support associations previously reported between PN and alcohol consumption or anthropometric measures(Cherry et al., 2009; Grant et al., 2010; Luma et al., 2012). In our cohort, only $10 \%$ of participants reported drinking alcohol ever and patients with SPN reported it less often than patients without neuropathy ( $7 \%$ vs. $12 \% ; p=0.02$ ). This apparently protective effect of alcohol has been previously described in observational studies(Pettersen et al., 2006) and in-vitro data suggest that cerebral neurons pre-treated with ethanol were resistant to the neurodegenerative effect of HIV protein gp120(Collins, Neafsey, \& Zou, 2000). Alternatively, although the effect of alcohol is adjusted for job status, it may be possible that alcohol consumption was associated with other socio-economic variables we did not measure. 
After starting second line therapy, we observed a significant reduction in the prevalence of SPN by week 96. However, the prevalence of signs suggestive of PN regardless of symptoms showed a smaller (though still significant) decline in response to second line treatment whereas APN actually increased progressively during follow up consistent with previous observations(Ellis et al., 2010; S. R. Evans et al., 2011). There is likely a complex interplay of factors explaining these changes in secondline therapy. Firstly, re-establishing VL control, treatment of opportunistic infections and general recovery of health might contribute to the initial reduction in symptoms. This decrease in SPN prevalence may perhaps be augmented by the confusion of non-neuropathy symptoms with neuropathy symptoms due to discrepancies between terms used to describe neuropathic pain in local African languages and English(Shaikh, Bentley, \& Kamerman, 2013). The cessation of d4T used in first-line may also have contributed to some of the symptomatic improvement(S. R. Evans et al., 2011) although we did not find any advantage to NRTI-free regimens tested in EARNEST (PI/RAL or PImono). Most patients in the PI/NRTI group were treated with TDF, which is unlikely to cause PN, but some (14\%) were exposed to $d d l$ in this group.

Symptom decrease with recovery of health on second line may be masking an underlying trend of neuropathy progression. One additional possibility to consider is that the PI contributed to some of the neuropathy progression in second line(Chen et al., 2013a; Pettersen et al., 2006). Although the exact mechanism for the association between PI and PN is not known(Ellis et al., 2008; Lichtenstein et al., 2005), in-vitro data suggest that exposure to indinavir can induce neuronal degeneration in dorsal root ganglion cultures(Pettersen et al., 2006). Furthermore, PI exposure has been associated with insulin resistance and development of diabetes mellitus (DM)(Paik \& Kotler, 2011) which may also lead to PN in both general and HIV-infected populations. However, we did not see any association between PN and DM.

Limitations of this study include the limited information available on past medical history and the use of non-ART medication prior to study entry (only medications in the last 10 weeks were collected). Clinical assessments in our study were performed by non-neurologists but medically qualified investigators using a rigorous case definition based on a tool previously validated in African settings(Luma et al., 2012; Maritz et al., 2010; Wadley et al., 2011). There were large differences between the sites in prevalence (after adjusting for other associations) that might suggest the possibility of systematic differences in the way the tests were applied. However, the fact that the prevalence of neuropathy in the three sites in Kampala was remarkably similar (25-28\%) whereas the other six Ugandan sites, located elsewhere in the country and with differing ethnic groups, also showed similar but much lower prevalence (0-9\%) provides some support for the belief that these differences reflect true population differences rather than erratic application of the tool.

In conclusion, our study provides evidence of high prevalence of SPN in HIV-positive patients from Sub-Saharan African countries at the time of first-line failure and during PI-based second-line therapy. In addition to well-recognised risk factors such as age, female gender and low CD4 count, SPN appeared to be strongly associated with toxic effects of isoniazid used to treat TB episodes, highlighting the importance of ensuring that pyridoxine is prescribed with TB treatment. The potential contribution to PIs to maintaining the high rate of neuropathy during second line therapy and management strategies to treat neuropathy deserve further investigation. 
Table 1: Characteristics at switch to second-line (baseline)

\begin{tabular}{|c|c|c|c|c|}
\hline & $\begin{array}{c}\text { PN } \\
(N=279)\end{array}$ & $\begin{array}{l}\text { no } P N \\
(N=972)\end{array}$ & $\begin{array}{c}\text { Total } \\
(\mathrm{N}=1251)^{\mathrm{a}}\end{array}$ & $\mathbf{P}$ \\
\hline \multicolumn{5}{|l|}{ Demographic characteristics } \\
\hline Female - n(\%) & $162(58 \%)$ & $564(58 \%)$ & 726 (58\%) & 0.99 \\
\hline Age - median (IQR) & $41(35-47)$ & $36(30-43)$ & $37(31-44)$ & $<0.0001$ \\
\hline Height cm - median(IQR) & $167(159-174)$ & $164(157-171)$ & $164(158-172)$ & 0.001 \\
\hline $\mathrm{BMI} \mathrm{kg} / \mathrm{m}^{2-}$ median (IQR) & $20(18-23)$ & $21(18-24)$ & $21(18-23)$ & 0.20 \\
\hline \multicolumn{5}{|l|}{ CD4 cells/mm3 } \\
\hline median (IQR) & $55(21-113)$ & $76(33-154)$ & $71(30-147)$ & $<0.0001$ \\
\hline$<100$ & $197(71 \%)$ & $572(59 \%)$ & 769 (61\%) & \\
\hline \multicolumn{5}{|l|}{ Viral load copies/ml } \\
\hline Median & 81762 & 64529 & 67500 & 0.03 \\
\hline (IQR) & $(29442-227600)$ & $(21346-178978)$ & (22818-193000) & \\
\hline$\geq 100,000$ & 135 (48\%) & 379 (39\%) & $514(41 \%)$ & \\
\hline \multicolumn{5}{|l|}{ WHO disease stage } \\
\hline $\begin{array}{l}\text { WHO stage } 3 / 4 \text { condition - } \\
n / \text { total } n(\%)\end{array}$ & 169/209 (81\%) & $429 / 538(80 \%)$ & $598 / 747$ (80\%) & 0.73 \\
\hline \multicolumn{5}{|l|}{ ART history } \\
\hline $\begin{array}{l}\text { Years on combination ART - median } \\
\text { (IQR) }\end{array}$ & $4.3(2.9-5.6)$ & $3.9(2.7-5.3)$ & $4.0(2.8-5.4)$ & 0.06 \\
\hline \multicolumn{5}{|l|}{ Ever taken first-line - $\mathrm{n}(\%)$} \\
\hline Nevirapine & $252(90 \%)$ & $823(85 \%)$ & 1075 (86\%) & 0.02 \\
\hline Zidovudine & $172(62 \%)$ & $682(70 \%)$ & 854 (68\%) & 0.007 \\
\hline Stavudine & 199 (71\%) & $557(57 \%)$ & 756 (60\%) & $<0.0001$ \\
\hline Tenofovir & $31(11 \%)$ & $149(15 \%)$ & $180(14 \%)$ & 0.08 \\
\hline \multicolumn{5}{|l|}{ Laboratory parameters } \\
\hline Haemoglobin g/dL -median (IQR) & $11.7(10.3-13.2)$ & $12.2(10.9-13.4)$ & $12.1(10.7-13.4)$ & 0.02 \\
\hline Fasting glucose $\mathrm{mmol} / \mathrm{L}$ - median (IQR) & $4.6(4.3-5.0)$ & $4.5(4.1-4.9)$ & $4.5(4.2-4.9)$ & 0.01 \\
\hline Creatinine mg/dL - median (IQR) & $0.8(0.6-1.0)$ & $0.7(0.6-0.9)$ & $0.7(0.6-0.9)$ & $<0.0001$ \\
\hline \multicolumn{5}{|l|}{ Medical history } \\
\hline Diabetes mellitus - n/total n(\%) & $7 / 279(3 \%)$ & $15 / 967(2 \%)$ & $22 / 1246(2 \%)$ & 0.29 \\
\hline Tuberculosis - n(\%) & 105 (38\%) & $225(23 \%)$ & $330(26 \%)$ & $<0.0001$ \\
\hline $\begin{array}{l}\text { Cardiovascular disease (CVD) - n/total } \\
\mathrm{n}(\%)\end{array}$ & $29 / 279(10 \%)$ & $47 / 971(5 \%)$ & $76 / 1250(6 \%)$ & 0.001 \\
\hline Family history of CVD - n/total n(\%) & $63 / 218(29 \%)$ & $121 / 736$ (16\%) & 184/954 (19\%) & $<0.0001$ \\
\hline $\begin{array}{l}\text { Alcohol consumption (ever) }{ }^{b}-n / \text { total } \\
n(\%)\end{array}$ & $18 / 269(7 \%)$ & $95 / 823(12 \%)$ & $113 / 1092(10 \%)$ & 0.03 \\
\hline Smoke exposure (ever) ${ }^{c}-n /$ total $n(\%)$ & $55 / 278(20 \%)$ & $119 / 970(12 \%)$ & $174 / 1248(14 \%)$ & 0.002 \\
\hline \multicolumn{5}{|l|}{$\begin{array}{l}\text { Concomitant medication (last } 10 \\
\text { weeks) }\end{array}$} \\
\hline Isoniazid - n(\%) & $42(15 \%)$ & $59(6 \%)$ & $101(8 \%)$ & $\begin{array}{l}<0.0001 \\
<0.00\end{array}$ \\
\hline Ethambutol - n(\%) & $39(14 \%)$ & $54(6 \%)$ & $93(7 \%)$ & 01 \\
\hline Pyrazinamide - n(\%) & $34(12 \%)$ & $46(5 \%)$ & $80(6 \%)$ & $<0.0001$ \\
\hline
\end{tabular}




$$
\begin{aligned}
& \text { Rifampicin }-\mathrm{n}(\%) \\
& \text { Fluclonazole }-\mathrm{n}(\%) \\
& \text { Ciprofloxacin }-\mathrm{n}(\%) \\
& \text { Cotrimoxazole }-\mathrm{n}(\%)
\end{aligned}
$$

\section{Socio-economic factors}

Employment status

Available

Employed

Student

Unemployed-ill health

Unemployed- lack of jobs

Household monthly income - n(\%)

Available

$<\$ 50$

$\$ 50-\$ 200$

$\geq \$ 200$

Centre

Kampala (JCRC)
Kampala (IDI)
Kampala (Nsambya)
Zimbabwe
Others $^{d}$

$$
\begin{gathered}
32(11 \%) \\
25(9 \%) \\
15(5 \%) \\
256(92 \%)
\end{gathered}
$$

279

$161(58 \%)$

$2(1 \%)$

66 (24\%)

$50(18 \%)$

238

87 (37\%)

$90(38 \%)$

$61(26 \%)$

$60(22 \%)$

$54(19 \%)$

$13(5 \%)$

$117(42 \%)$

35 (13\%)
47 (5\%)

61 (6\%)

79 (6\%)

$86(7 \%)$

42 (3\%)

1162 (93\%)

906 (93\%)

$<0.0001$

0.12

0.04

0.41
1246

785(63\%)

$97(8 \%)$

175 (14\%)

$189(15 \%)$

1086

513 (47\%)

378 (35\%)

$<0.0001$

$195(18 \%)$

231 (18\%)

215 (17\%)

47 (4\%)

$<0.0001$

$146(15 \%) \quad 263(21 \%)$

$460(47 \%)$

All $p$ values from logistic regression. MFP was used for continuous variables to allow of non-linear relationships

${ }^{a}$ This table includes complete cases. Multivariable analysis is on multiply imputed data so includes an additional 6 participants who have missing symptomatic neuropathy status

${ }^{\mathrm{b}}$ For model including units, $\mathrm{p}=0.49$ for units of alcohol consumed in a week.

${ }^{\mathrm{c}}$ Only 20 participants currently smoked so current and ex-smoker grouped into ever smokers.

${ }^{d}$ Site prevalence varies from $0 \%-11 \%$ in 9 sites with $31-97$ participants per site. Site geographical locations were rural Uganda, Kenya, and Zambia 
Table 2: Multivariable analysis of factors associated with Symptomatic Peripheral Neuropathy at first-line ART failure

\begin{tabular}{|c|c|c|c|c|}
\hline & $\begin{array}{l}\text { Unadjusted Odds } \\
\text { ratio }(95 \% \mathrm{Cl})^{*}\end{array}$ & P value & $\begin{array}{l}\text { Adjusted Odds } \\
\text { ratio }(95 \% \mathrm{Cl})\end{array}$ & $P$ value \\
\hline Sex-female & $1.00(0.76,1.31)$ & 0.99 & $1.65(1.13,2.41)$ & 0.01 \\
\hline Age -years & $1.05(1.04,1.06)$ & $<0.0001$ & $1.04(1.02,1.06)$ & $<0.0001$ \\
\hline CD4 (per doubling) & $0.82(0.76,0.88)$ & $<0.0001$ & $0.83(0.76,0.92)$ & $<0.0001$ \\
\hline TB & $2.00(1.51,2.66)$ & $<0.0001$ & $1.86(1.33,2.60)$ & $<0.0001$ \\
\hline Smoke exposure (ever) & $1.76(1.24,2.51)$ & 0.002 & $1.61(1.02,2.53)$ & 0.04 \\
\hline Alcohol use & $0.55(0.33,0.93)$ & 0.03 & $0.54(0.30,0.96)$ & 0.04 \\
\hline Creatinine (per $0.1 \mathrm{mg} / \mathrm{dl}$ inc) & $1.13(1.07,1.18)$ & $<0.0001$ & $1.09(1.03,1.16)$ & 0.006 \\
\hline \multicolumn{5}{|l|}{ Centre } \\
\hline Kampala (JCRC) & 1 & $<0.0001$ & 1 & $<0.0001$ \\
\hline Kampala (IDI) & $0.96(0.62,1.46)$ & & $0.82(0.51,1.33)$ & \\
\hline Kampala (Nsambya) & $1.09(0.54,2.20)$ & & $1.08(0.48,2.39)$ & \\
\hline Zimbabwe & $2.28(1.56,3.35)$ & & $1.07(0.67,1.70)$ & \\
\hline Others ${ }^{+}$ & $0.22(0.14,0.34)$ & & $0.20(0.12,0.32)$ & \\
\hline Viral Load (per doubling) & $1.07(1.00,1.14)$ & 0.03 & $1.07(1.00,1.15)$ & 0.06 \\
\hline Glucose (per doubling) & $1.63(1.00,2.66)$ & 0.05 & $1.71(0.96,3.05)$ & 0.07 \\
\hline Family history of CVD & $2.07(1.45,2.94)$ & $<0.0001$ & $1.49(0.98,2.27)$ & 0.06 \\
\hline Tenofovir exposure & $0.69(0.46,1.04)$ & 0.08 & $0.65(0.40,1.06)$ & 0.08 \\
\hline Nevirapine exposure & $1.69(1.10,2.61)$ & 0.02 & $1.56(0.95,2.57)$ & 0.08 \\
\hline \multicolumn{5}{|l|}{ Employment status } \\
\hline Employed & 1 & $<0.0001$ & 1 & 0.07 \\
\hline Student & $0.08(0.02,0.33)$ & & $0.35(0.08,1.53)$ & \\
\hline Unemployed- too ill & $2.35(1.65,3.33)$ & & $1.47(0.97,2.23)$ & \\
\hline Unemployed-no jobs & $1.39(0.97,2.01)$ & & $1.37(0.90,2.07)$ & \\
\hline
\end{tabular}

* contains only variables included in the multivariable model

† Site prevalence varies from $0 \%-11 \%$ in 9 sites with 31-97 participants per site. Site geographical locations were rural Uganda, Kenya, and Zambia

Table 3: Symptomatic peripheral neuropathy arm comparison

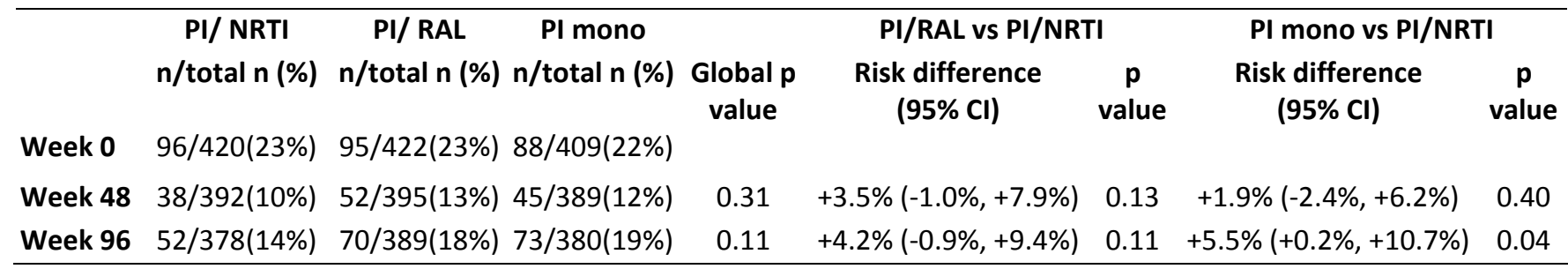


Fig. 1 Percentage of Patients with Peripheral Neuropathy during the study period by treatment arm

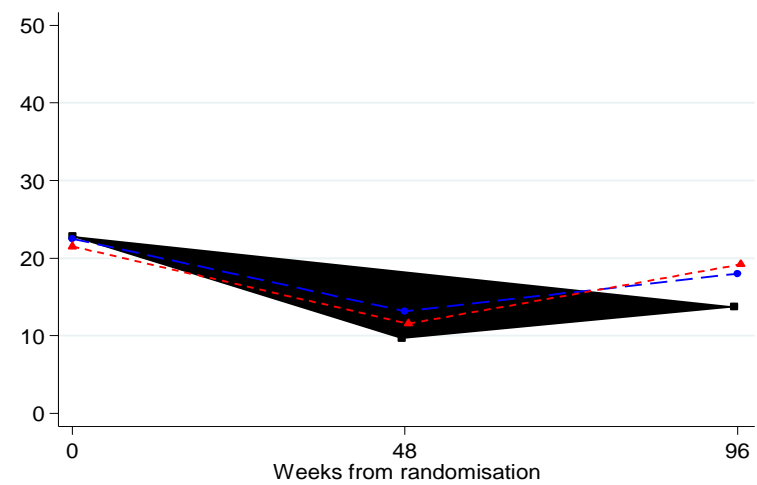

Global GEE $\mathrm{p}=0.30$

Weeks from randomisation PIRAL VS PINRTI GEE $\mathrm{p}=0.21$
PIImono vs PINRTI GEE $\mathrm{p}=0.14$

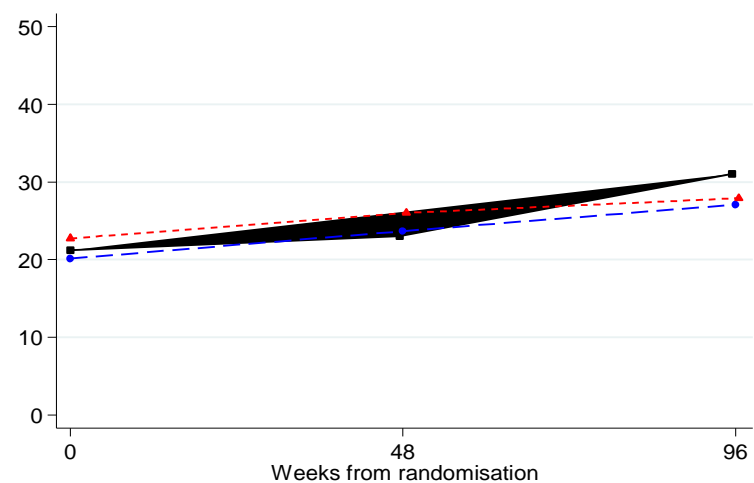

Global GEE $\mathrm{p}=0.65$

Weeks from randomisation PImono vs PI/NRTI GEE $\mathrm{p}=0.37$

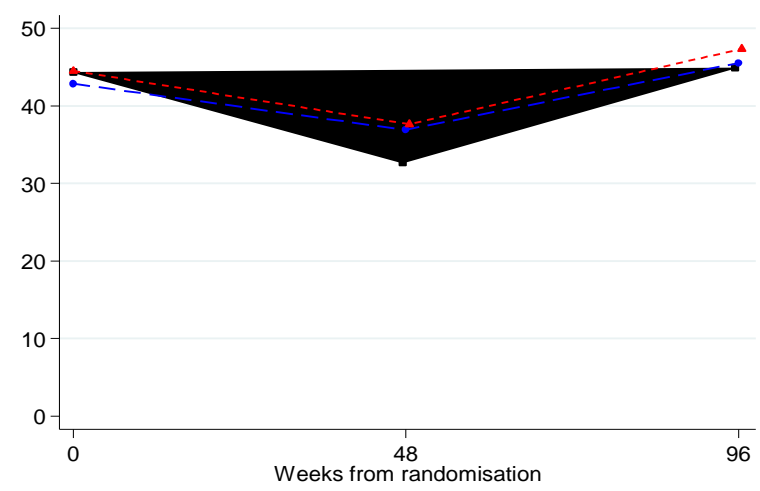

Global GEE $p=0.75$
PI/RAL VS PINNRTI GEE $p=0.48$
PImono vs PINRTI GEE $\mathrm{p}=0.50$

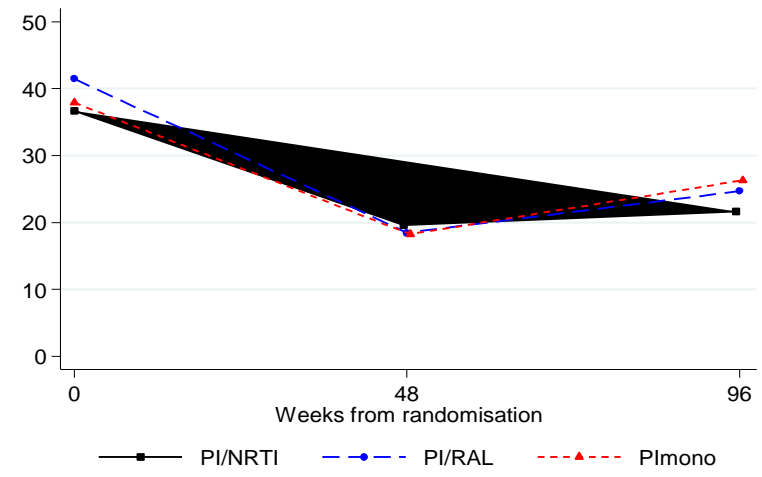

Global GEE $\mathrm{p}=0.35$

PI/RAL VS PI/NRTIIGEE $\mathrm{p}=0.24$ 
Fig. 2 Number and proportion of participants by SNP status during the study period

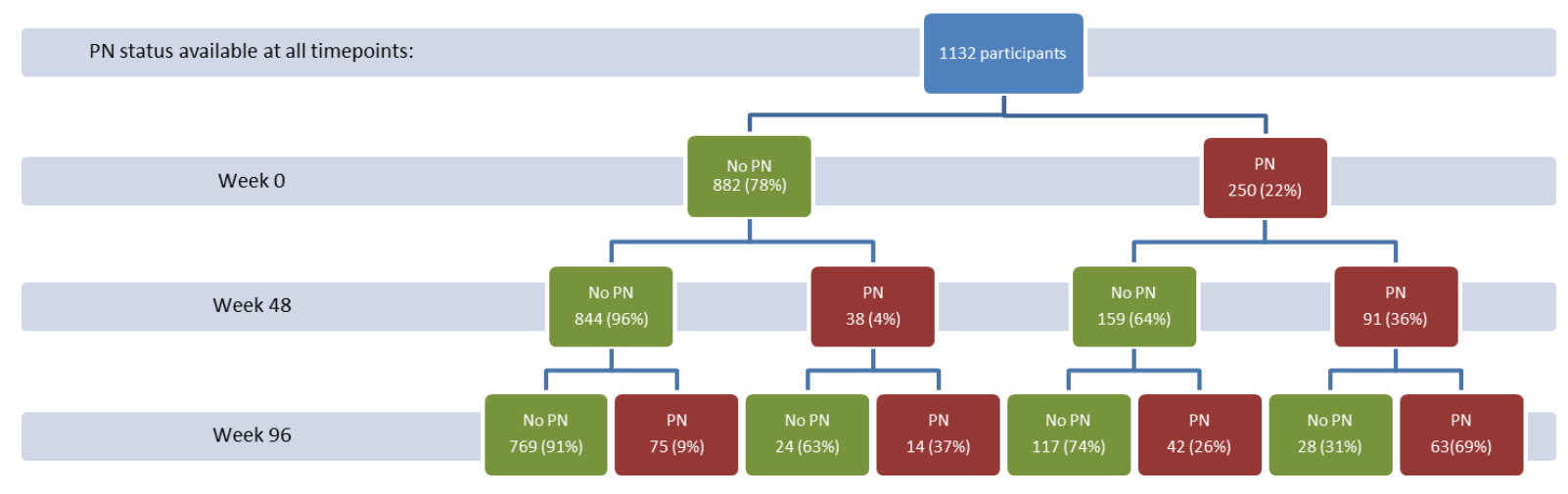




\section{ACKNOWLEDEGEMENTS}

We thank all the patients and staff from all the centres participating in the EARNEST trial.

Funding and in-kind support: The EARNEST trial was funded by the European and Developing Countries Clinical Trials Partnership (EDCTP) with contributions from the Medical Research Council, UK, Institito de Salud Carlos III, Spain, Irish Aid, Ireland, Swedish International Development Cooperation Agency (SIDA), Sweden, Instituto Superiore di Sanita (ISS), Italy and Merck, USA. Substantive in-kind contributions were made by the Medical Research Council Clinical Trials Unit, UK, CINECA, Bologna, Italy, Janssen Diagnostics, Mechelen, Belgium; GSK, UK; Abbott Laboratories, USA. Trial medication was donated by AbbVie, Merck, Pfizer, GSK and Gilead

Potential conflicts of interest: NIP was the EDCTP grant recipient for this trial. NIP, ASW, MT, JT and AAP are employed by the MRC-UK. NIP, ASW and AAP have received funding support for other studies from GSK or Janssen. AM, GM and HM have received support from the Research Councils-UK for research projects. NIP has received payments for lectures from Merck, Janssen and AbbVie. AAP has received payments for lectures from Janssen. Institutional payment has been received from Gilead Sciences because of a lecture given by ASW. ASW has been DSMB member- for studies sponsored by Tibotec.

\section{The EARNEST Trial Team are:}

\section{Participating Sites}

\section{Uganda:}

JCRC Kampala (African trial co-ordinating centre; 231) E Agweng, P Awio, G Bakeinyaga, C Isabirye, U Kabuga, S Kasuswa, M Katuramu, C Kityo, F Kiweewa, H Kyomugisha, E Lutalo, P Mugyenyi, D Mulima, H Musana, G Musitwa, V Musiime, M Ndigendawan, H Namata, J Nkalubo, P Ocitti Labejja, P Okello, P Olal, G Pimundu, P Segonga, F Ssali, Z Tamale, D Tumukunde, W Namala, R Byaruhanga, J Kayiwa, J Tukamushaba.

IDI, Kampala (216): G Bihabwa, E Buluma, P Easterbrook, A Elbireer, A Kambugu, D Kamya, M Katwere, R Kiggundu, C Komujuni, E Laker, E Lubwama, I Mambule, J Matovu, A Nakajubi, J Nakku, R Nalumenya, L Namuyimbwa, F Semitala, B Wandera, J Wanyama

JCRC, Mbarara (97): H Mugerwa, A Lugemwa, E Ninsiima, T Ssenkindu, S Mwebe, L Atwine, H William, C Katemba, S Abunyang, M Acaku, P Ssebutinde, H Kitizo, J Kukundakwe, M Naluguza, K Ssegawa, Namayanja, F Nsibuka, P Tuhirirwe, M Fortunate

JCRC Fort Portal (66): J Acen, J Achidri, A Amone, M. Chamai, J Ditai, M Kemigisa, M Kiconco, C Matama, D Mbanza, F Nambaziira, M Owor Odoi, A Rweyora, G. Tumwebaze

San Raphael of St Francis Hospital, Nsambya (48): H Kalanzi, J Katabaazi , A Kiyingi, M Mbidde, M. Mugenyi, R Mwebaze, P Okong, I Senoga

JCRC Mbale (47): M Abwola, D Baliruno, J Bwomezi, A Kasede, M Mudoola, R Namisi, F Ssennono, S Tuhirwe 
JCRC Gulu (43): G Abongomera, G Amone, J Abach, I Aciro, B Arach, P Kidega, J Omongin, E Ocung, W Odong, A Philliam

JCRC Kabale (33): H Alima, B Ahimbisibwe, E Atuhaire, F Atukunda, G Bekusike, A Bulegyeya, D. Kahatano, S Kamukama, J Kyoshabire, A Nassali, A Mbonye, T M Naturinda, Ndukukire, A Nshabohurira, H. Ntawiha, A Rogers, M Tibyasa;

JCRC Kakira (31): S. Kiirya, D. Atwongeire, A. Nankya, C. Draleku, D. Nakiboneka, D. Odoch, L. Lakidi, R. Ruganda, R. Abiriga, M. Mulindwa, F. Balmoi, S. Kafuma, E. Moriku

\section{Zimbabwe}

University of Zimbabwe Clinical Research Centre, Harare (265): J Hakim, A Reid, E Chidziva, GMusoro, C Warambwa, G Tinago, S Mutsai, M Phiri, S Mudzingwa, T Bafana, V Masore, C Moyo, R Nhema, S Chitongo.

\section{Malawi}

College of Medicine, University of Malawi, Blanytre (92): Rob Heyderman, Lucky Kabanga, Symon Kaunda, Aubrey Kudzala, Linly Lifa, Jane Mallewa, Mike Moore, Chrissie Mtali, George Musowa, Grace Mwimaniwa, Rosemary Sikwese, Joep van Oosterhout, Milton Ziwoya

Mzuzu Central Hospital, Mzuzu (19): H Chimbaka. B Chitete, S Kamanga, T Kayinga E Makwakwa, R Mbiya, M Mlenga, T Mphande, C Mtika, G Mushani, O Ndhlovu, M Ngonga, I Nkhana, R Nyirenda

\section{Kenya}

Moi Teaching and Referral Hospital (52): P Cheruiyot, C Kwobah, W Lokitala Ekiru, M Mokaya, A Mudogo, A Nzioka, A Siika, M Tanui, S Wachira, K Wools-Kaloustian

\section{Zambia}

University Teaching Hospital (37): P Alipalli, E Chikatula, J Kipaila, I Kunda, S Lakhi, J Malama, W Mufwambi, L Mulenga, P Mwaba, E Mwamba, A Mweemba, M Namfukwe

The Aids Support Organisation (TASO), Uganda: E Kerukadho, B Ngwatu, J Birungi

MRC Clinical Trials Unit: N Paton, J Boles, A Burke, L Castle, S Ghuman, L Kendall, A Hoppe, S Tebbs, $M$ Thomason, J Thompson, S Walker, J Whittle, H Wilkes, $\mathrm{N}$ Young

Monitors: C Kapuya, F Kyomuhendo, D Kyakundi, N Mkandawire, S Mulambo, S Senyonjo

Clinical Expert Review Committee: B Angus, A Arenas-Pinto, A Palfreeman, F Post, D Ishola

European Collaborators: J Arribas, B Colebunders, M Floridia, M Giuliano, P Mallon, P Walsh, M De Rosa, E Rinaldi

Trial Steering Committee: I Weller (Chair), C Gilks, J Hakim, A Kangewende, S Lakhi, E Luyirika, F Miiro, P Mwamba, P Mugyenyi, S Ojoo, N Paton, S Phiri, J van Oosterhout, A Siika, S Walker, A Wapakabulo, 
Data Monitoring Committee: T Peto (Chair), N French, J Matenga

Pharmaceutical companies: G Cloherty, J van Wyk, M Norton, S Lehrman, P Lamba, K Malik, J Rooney, W Snowden, J Villacian

\section{REFERENCES}

Arenas-Pinto, A., Bhaskaran, K., Dunn, D., \& Weller, I. V. (2008). The risk of developing peripheral neuropathy induced by nucleoside reverse transcriptase inhibitors decreases over time: evidence from the Delta trial. Antivir Ther, 13(2), 289-295.

Biraguma, J., \& Rhoda, A. (2012). Peripheral neuropathy and quality of life of adults living with HIV/AIDS in the Rulindo district of Rwanda. SAHARA J, 9(2), 88-94.

Breen, R. A., Miller, R. F., Gorsuch, T., Smith, C. J., Schwenk, A., Holmes, W., et al. (2006). Adverse events and treatment interruption in tuberculosis patients with and without HIV co-infection. Thorax, 61(9), 791-794.

Cettomai, D., Kwasa, J., Kendi, C., Birbeck, G. L., Price, R. W., Bukusi, E. A., et al. (2010). Utility of quantitative sensory testing and screening tools in identifying HIV-associated peripheral neuropathy in Western Kenya: pilot testing. PLoS One, 5(12), e14256.

Chen, H., Clifford, D. B., Deng, L., Wu, K., Lee, A. J., Bosch, R. J., et al. (2013a). Peripheral neuropathy in ART-experienced patients: prevalence and risk factors. J Neurovirol, 19(6), 557-564.

Cherry, C. L., Affandi, J. S., Imran, D., Yunihastuti, E., Smyth, K., Vanar, S., et al. (2009). Age and height predict neuropathy risk in patients with HIV prescribed stavudine. Neurology, 73(4), 315-320.

Childs, E. A., Lyles, R. H., Selnes, O. A., Chen, B., Miller, E. N., Cohen, B. A., et al. (1999). Plasma viral load and CD4 lymphocytes predict HIV-associated dementia and sensory neuropathy. Neurology, $52(3), 607-613$.

Collins, M. A., Neafsey, E. J., \& Zou, J. Y. (2000). HIV-I gpI20 neurotoxicity in brain cultures is prevented by moderate ethanol pretreatment. Neuroreport, 11(6), 1219-1222.

Dean, G. L., Edwards, S. G., Ives, N. J., Matthews, G., Fox, E. F., Navaratne, L., et al. (2002). Treatment of tuberculosis in HIV-infected persons in the era of highly active antiretroviral therapy. AIDS, 16(1), 75-83.

Ellis, R. J., Evans, S. R., Clifford, D. B., Moo, L. R., McArthur, J. C., Collier, A. C., et al. (2005). Clinical validation of the NeuroScreen. J Neurovirol, 11(6), 503-511.

Ellis, R. J., Marquie-Beck, J., Delaney, P., Alexander, T., Clifford, D. B., McArthur, J. C., et al. (2008). Human immunodeficiency virus protease inhibitors and risk for peripheral neuropathy. Ann Neurol, 64(5), 566-572.

Ellis, R. J., Rosario, D., Clifford, D. B., McArthur, J. C., Simpson, D., Alexander, T., et al. (2010). Continued high prevalence and adverse clinical impact of human immunodeficiency virus-associated sensory neuropathy in the era of combination antiretroviral therapy: the CHARTER Study. Arch Neurol, 67(5), 552-558. 
Evans, D., Takuva, S., Rassool, M., Firnhaber, C., \& Maskew, M. (2012). Prevalence of peripheral neuropathy in antiretroviral therapy naive HIV-positive patients and the impact on treatment outcomes--a retrospective study from a large urban cohort in Johannesburg, South Africa. J Neurovirol, 18(3), 162-171.

Evans, S. R., Ellis, R. J., Chen, H., Yeh, T. M., Lee, A. J., Schifitto, G., et al. (2011). Peripheral neuropathy in HIV: prevalence and risk factors. AIDS, 25(7), 919-928.

Grant, A. D., Mngadi, K. T., van Halsema, C. L., Luttig, M. M., Fielding, K. L., \& Churchyard, G. J. (2010). Adverse events with isoniazid preventive therapy: experience from a large trial. AIDS, 24 Suppl 5, S29-36.

Kamerman, P. R., Wadley, A. L., \& Cherry, C. L. (2012). HIV-associated sensory neuropathy: risk factors and genetics. Curr Pain Headache Rep, 16(3), 226-236.

Kampira, E., Kumwenda, J., van Oosterhout, J. J., \& Dandara, C. (2013). Mitochondrial DNA subhaplogroups LOa2 and L2a modify susceptibility to peripheral neuropathy in malawian adults on stavudine containing highly active antiretroviral therapy. J Acquir Immune Defic Syndr, 63(5), 647652.

Lichtenstein, K. A., Armon, C., Baron, A., Moorman, A. C., Wood, K. C., \& Holmberg, S. D. (2005). Modification of the incidence of drug-associated symmetrical peripheral neuropathy by host and disease factors in the HIV outpatient study cohort. Clin Infect Dis, 40(1), 148-157.

Luma, H. N., Tchaleu, B. C., Doualla, M. S., Temfack, E., Sopouassi, V. N., Mapoure, Y. N., et al. (2012). HIV-associated sensory neuropathy in HIV-1 infected patients at the Douala General Hospital in Cameroon: a cross-sectional study. AIDS Res Ther, 9(1), 35.

Maritz, J., Benatar, M., Dave, J. A., Harrison, T. B., Badri, M., Levitt, N. S., et al. (2010). HIV neuropathy in South Africans: frequency, characteristics, and risk factors. Muscle Nerve, 41(5), 599606.

Marra, C. M., Boutin, P., \& Collier, A. C. (1998). Screening for distal sensory peripheral neuropathy in HIV-infected persons in research and clinical settings. Neurology, 51(6), 1678-1681.

Mehta, S. A., Ahmed, A., Laverty, M., Holzman, R. S., Valentine, F., \& Sivapalasingam, S. (2011). Sex differences in the incidence of peripheral neuropathy among Kenyans initiating antiretroviral therapy. Clin Infect Dis, 53(5), 490-496.

Nakamoto, B. K., McMurtray, A., Davis, J., Valcour, V., Watters, M. R., Shiramizu, B., et al. (2010). Incident neuropathy in HIV-infected patients on HAART. AIDS Res Hum Retroviruses, 26(7), 759-765.

Paik, I. J., \& Kotler, D. P. (2011). The prevalence and pathogenesis of diabetes mellitus in treated HIVinfection. Best Pract Res Clin Endocrinol Metab, 25(3), 469-478.

Paton, N. I., Kityo, C., Hoppe, A., Reid, A., Kambugu, A., Lugemwa, A., et al. (2014). Assessment of second-line antiretroviral regimens for HIV therapy in Africa. N Engl J Med, 371(3), 234-247. 
Pettersen, J. A., Jones, G., Worthington, C., Krentz, H. B., Keppler, O. T., Hoke, A., et al. (2006). Sensory neuropathy in human immunodeficiency virus/acquired immunodeficiency syndrome patients: protease inhibitor-mediated neurotoxicity. Ann Neurol, 59(5), 816-824.

Shaikh, A., Bentley, A., \& Kamerman, P. R. (2013). Symptomatology of peripheral neuropathy in an African language. PLoS One, 8(5), e63986.

van Buuren, S., Boshuizen, H. C., \& Knook, D. L. (1999). Multiple imputation of missing blood pressure covariates in survival analysis. Stat Med, 18(6), 681-694.

van der Watt, J. J., Harrison, T. B., Benatar, M., \& Heckmann, J. M. (2011). Polyneuropathy, antituberculosis treatment and the role of pyridoxine in the HIV/AIDS era: a systematic review. Int $J$ Tuberc Lung Dis, 15(6), 722-728.

van Oosterhout, J. J., Mallewa, J., Kaunda, S., Chagoma, N., Njalale, Y., Kampira, E., et al. (2012). Stavudine toxicity in adult longer-term ART patients in Blantyre, Malawi. PLoS One, 7(7), e42029.

Wadley, A. L., Cherry, C. L., Price, P., \& Kamerman, P. R. (2011). HIV neuropathy risk factors and symptom characterization in stavudine-exposed South Africans. J Pain Symptom Manage, 41(4), 700706.

Westreich, D. J., Sanne, I., Maskew, M., Malope-Kgokong, B., Conradie, F., Majuba, P., et al. (2009). Tuberculosis treatment and risk of stavudine substitution in first-line antiretroviral therapy. Clin Infect Dis, 48(11), 1617-1623.

Wright, E., Brew, B., Arayawichanont, A., Robertson, K., Samintharapanya, K., Kongsaengdao, S., et al. (2008). Neurologic disorders are prevalent in HIV-positive outpatients in the Asia-Pacific region. Neurology, 71(1), 50-56. 